\title{
Ações estratégicas desconectadas da Política de Saúde nas Conferências de Saúde de Ponta Grossa/ PR: óbice à efetiva participação social
}

\section{Strategic actions disconnected from municipal health Policy in the Health Conferences of Ponta Grossa/PR: obstacles to effective social participation}

\author{
Pedro Fauth Manhães Miranda* \\ Danuta Estrufika Cantóia Luiz*
}

\begin{abstract}
Resumo: As Conferências Municipais de Saúde são, desde 1988, instrumentos nacionais de Democracia Participativa, e hodiernamente estão muito difundidos na política brasileira. Porém, sua atuação ainda se encontra em desenvolvimento, inclusive quanto a proposição de ações estratégicas referentes à sua primordial finalidade: contribuir na formulação da política municipal de saúde. Assim, por meio de revisão bibliográfica e coleta de dados quantitativos sobre a atuação das $8^{a}$ e $9^{a}$ Conferências de Saúde de Ponta Grossa/PR, bem como da respectiva Secretaria Municipal de Saúde, este artigo procurou demonstrar que a proposição por tais órgãos de ações desconectadas de sua finalidade é um óbice à efetiva participação social na Administração Pública.
\end{abstract}

Palavras-chave: Administração Pública. Conferência Municipal de Saúde. Controle Social. Participação Social.

\begin{abstract}
The Municipal Health Conferences are, since 1988, national instruments of participatory democracy, and nowadays much diffused in Brazilian politics. However, their performance is still in development, including their proposal of strategic actions related to their primary purpose: helping formulating the municipal health policy. Thus, through literature review and collection of quantitative data on the performance of the $8^{\text {th }}$ and $9^{\text {th }}$ Health Conferences of Ponta Grossa/PR, as well as the Municipal Secretary of Health data, this article sought to show that the proposition by such organs of disconnected actions of its purpose is an obstacle to the effectiveness of social participation in public administration.
\end{abstract}

Keywords: Public Administration. Municipal Health Conferences. Social Control. Social Participation.

\footnotetext{
"Mestre em Ciências Sociais Aplicadas na Universidade Estadual de Ponta Grossa (UEPG); Graduado em Direito pela Universidade Estadual de Londrina (UEL); Graduando em Ciência Política pelo Centro Universitário Internacional (UNINTER). Professor Colaborador de Direito na Universidade Estadual de Ponta Grossa (UEPG); Professor de Sociologia no Instituto de Filosofia e Teologia Mater Ecclesiae (IFITEME). E-mail: pedromiranda.adv@gmail.com

"Doutora em Serviço Social pela Pontifícia Universidade Católica de São Paulo (PUC-SP). Mestre em Serviço Social (PUC-SP). Graduada em Serviço Social pela Universidade Estadual de Ponta Grossa (UEPG). Professora Associada do Departamento de Serviço Social da UEPG. E-mail: danutaluiz88@gmail.com
} 


\section{Introdução}

A política brasileira encontra-se, atualmente, muito mais socializada do que décadas atrás, tendo como um de seus marcos a Constituição de 1988 - a chamada "Carta Cidadã", cujo texto positivou a Democracia Participativa, que, aliada à Representativa, tem por objetivo suprir falhas e omissões desta. Para tanto, foram instituídas formas de controle social, ou seja, meios dos segmentos organizados da Sociedade Civil fiscalizarem a atuação estatal e auxiliarem na formulação de políticas públicas. Assim, a política - desde a implementação destas formas de controle social, dentre outras mudanças democráticas -, não mais se resume aos representantes eleitos pelo voto, nem a Sociedade Civil participa dela apenas nas eleições.

Paralelamente à participação, a redemocratização brasileira baseou-se também no expediente da descentralização. Implementadas na esfera política e na administrativa, tais medidas trouxeram novos sujeitos às relações de poder, ramificando-as para âmbitos mais locais, seja do Estado (prefeituras, secretarias, conselhos e conferências etc.), ou mesmo da Sociedade Civil (observatórios sociais, associações de bairro, agremiações etc.). Com a institucionalização destes órgãos e a instrumentalização de grupos sociais organizados, pôde ocorrer a potencialização de forças e sujeitos locais, tanto da Sociedade Civil como da Sociedade Política, abrindo possibilidades de construção de diálogos entre estas esferas.

Especificamente em relação às políticas públicas sociais - assistência social, saúde e educação -, o alinhamento das medidas participativas e descentralizadoras criou dois instrumentos fundamentais para a atual gestão pública: as Conferências de Políticas Públicas e os Conselhos de Políticas Públicas. Presentes em todas as instâncias da República Federativa do Brasil, tais órgãos promovem a inclusão de novos sujeitos nas relações de poder, além de descentralizar administrativamente a gestão das referidas políticas, municipalizando-as ${ }^{1}$.

\footnotetext{
${ }^{1}$ Vale ressaltar que a consideração, pela nossa Constituição, dos municípios como entidade político-administrativa estatal dotada de autonomia é "a grande característica de nossa federação, [sendo] a única de todos os Estados federais" a fazê-lo. (CASTRO
}

E tal discurso de socialização política é verídico, ao menos no campo formal das instituições. Pois a efetivação do referido controle social é algo muito mais complexo de ser verificado, como há de se demonstrar no presente artigo, que tem por objetivo analisar a atuação das $8^{\mathrm{a}} \mathrm{e}$ $9^{a}$ Conferências Municipais de Saúde de Ponta Grossa, por meio dos dados referentes às ações estratégicas apresentadas em desconexão para com a respectiva política de saúde.

O estudo justifica-se, assim, pelo crescente potencial de participação da Sociedade Civil na esfera política - seja a nível nacional, estadual ou municipal ${ }^{2}$. Contudo, a literatura especializada (DAGNINO, 2002; KRÜGER et al., 2012; TATAGIBA, 2002) indica, em grande parte das vezes, que, apesar de a redemocratização ter instituído os mencionados Conselhos e Conferências, dentre outras medidas participativas e descentralizadoras, tais instâncias nem sempre surtem os efeitos democráticos e emancipadores desejados, já que dependem de inúmeras determinantes para concretizar seus interesses. E este trabalho analisará uma destas determinantes, qual seja a aprovação de ações estratégicas, nos relatórios finais das Conferências Municipais de Saúde de Ponta Grossa - CMSPG, desconectadas de sua prevista finalidade político-administrativa.

O presente artigo é fruto da pesquisa realizada no Programa de Pós-Graduação em Ciências Sociais Aplicadas - Mestrado, da Universidade Estadual de Ponta Grossa, no período 2012-2014, intitulada "Expressões do Poder Local na Materialização das Conferências Municipais de Saúde de Ponta Grossa - 2009 e 2011" (MIRANDA, 2014).

O artigo, portanto, tem um recorte mais delimitado que o da pesquisa realizada no programa de mestrado, buscando demonstrar quantitativamente a existência de ações estratégicas propostas pela CMSPG e desconectadas da política de saúde, o que dificulta uma participação social mais efetiva nesta esfera da Administração Pública. Acreditamos que a percepção de tal

apud TAVARES, 2008, p.1021)

2 Segundo o IBGE (2012, p.209), em 2011, do total de 5.565 muni-
cípios brasileiros, apenas 12 não dispunham de um Conselho de
Saúde. Quanto às Conferências Municipais, o Relatório Final da
$14^{a}$ Conferência Nacional de Saúde (BRASIL, 2012, p.9) indicava
que, no mesmo ano, haviam sido promovidas 4.347 destas. 
problemática é o primeiro passo para que a atuação dos órgãos envolvidos neste processo possa ser aperfeiçoada, o que se mostra bastante positivo para a nossa política, já que seu potencial democrático é imenso.

Em face do objetivo proposto, a metodologia utilizada foi a do estudo de caso quantitativo, com revisão bibliográfica e pesquisa documental das seguintes fontes primárias: os relatórios finais das $8^{\mathrm{a}}$ e $9^{\mathrm{a}} \mathrm{CMSPG}$, bem como o plano plurianual de saúde do Governo de Ponta Grossa (20102013) e o plano anual (2012). Assim, a análise de dados sobre a atuação das CMSPG se deu sob duas frentes quantitativas: tanto a partir das ações estratégicas presentes nos relatórios finais das CMSPG, bem como quantas destas ações foram materializadas nos respectivos planos governamentais.

Neste sentido, este artigo foi estruturado de modo a, primeiramente, apresentar um breve histórico e conceituação da Democracia Participativa, com enfoque especial sobre as Conferências Municipais de Saúde de Ponta Grossa. Depois, exibimos a proposição de ações estratégicas desta instância, dividindo-as segundo eixos operacionais. Como nosso objetivo foca-se na análise das ações desconectadas da finalidade primária das CMSPG, o eixo das "outras" ações estratégicas (que não se refere especificamente à política de saúde) será o examinado com mais profundidade, para então demonstrarmos, ao final, a correlação entre tais dados e uma baixa recepção de tais ações pela Administração Pública (Secretaria Municipal de Saúde).

\section{A DEMOCRACIA E O CONTROLE SOCIAL NA SAÚDE}

\section{Democracia participativa}

A partir do conceito básico de Democracia governo exercido pelo povo -, e adotando como variável o nível de participação social na política, três são as principais formas que tal sistema de governo passou a assumir: a democracia direta, a representativa (ou indireta) e a participativa.

A primeira delas é a menos usual, pois demanda que todos os cidadãos opinem, por meio da Vontade Geral, sobre os rumos políticos tomados pelo Estado. Existente na Grécia antiga, onde os indivíduos considerados cidadãos eram poucos, foi descrita, no século XVIII, por Rousseau (1991). Em sua análise, o próprio pensador entendia que tal regime só poderia ser implantado em territórios nos quais houvesse a coexistência de quatro fatores: uma população numericamente reduzida; com simplicidade de costumes, que evitasse temas complexos; com igualdade entre as classes; e a inexistência de luxo. Assim, o filósofo iluminista termina por reconhecer que "[...] jamais existiu, jamais existirá uma democracia verdadeira. [...] Se existisse um povo de deuses, governar-se-ia democraticamente. Governo tão perfeito não convém aos homens". (ROUSSEAU, 1991, p.84-86). Não obstante, tal forma democrática persiste na atualidade, por meio de alguns instrumentos políticos, como o referendo e o plebiscito.

Já a vertente representativa é mais comum entre países que adotam a Democracia, pois ao mesmo tempo em que entende o povo como titular do poder político, facilita o exercício deste pelos representantes. Tal construção política se explicita no parágrafo único, art. $1^{\circ}$ de nossa Constituição Federal: "todo o poder emana do povo, que o exerce por meio de representantes eleitos" (BRASIL, 1988). Neste caso, a participação política se dá, principalmente, através do sufrágio, por meio do qual os cidadãos escolhem, por maioria, os representantes. Entretanto, sem uma vigilância adequada e constante pelos eleitores, a representatividade prometida no período de campanha pode se perder diante de interesses políticos.

O descontentamento para com a democracia representativa tornou-se lugar comum, sendo os principais fatores, segundo Delgado (apud WOLKMER, 2003, p.92): a) sucessivos descumprimentos de programas; b) a corrupção da classe política; c) declínio de vastos setores sociais; d) complexidade das demandas e especialização técnica; e) crise dos discursos de legitimação; e, finalmente, f) influência dos meios de comunicação.

Mas apesar de muito noticiada, poucas alternativas à crise da representação política são colocadas em prática. Uma destas alternativas é o último sistema democrático aqui analisado, a Democracia Participativa. 
É possível, portanto, perceber que a teoria hegemônica da democracia, no momento em que é reaberto o debate democrático com o fim da guerra fria e o aprofundamento do processo de globalização, está frente a um conjunto de questões não resolvidas que remetem ao debate entre democracia representativa e democracia participativa. Essas questões se colocam de modo mais agudo naqueles países nos quais existe maior diversidade étnica; entre aqueles grupos que têm maior dificuldade para ter os seus direitos reconhecidos (Benhabib, 1996; Young, 2000); nos países nos quais a questão da diversidade de interesses se choca com o particularismo de elites econômicas (Bóron, 1994). (SANTOS, 2002, p.50)

E não nos parece coincidência encontrarmos evidenciados, no Brasil, os problemas relatados por Santos. Portanto, é sintomático deste período, e também da conjuntura de redemocratização, pela qual o Brasil passa no final da década de 80 , o maior destaque fornecido à Democracia Participativa e seus instrumentos políticos. Surgida em resposta à crise da representação política, não visa substituí-la, mas, sim, suprir suas falhas, de modo a criar espaços de diálogo entre segmentos organizados da Sociedade Civil e representantes políticos. Deste modo, antes de adentrarmos nas especificidades da pesquisa, faz-se necessário reiterar o caráter complementar da Democracia Participativa, muito distante daquele divulgado por figuras elitistas do modelo representativo ${ }^{3}$.

Em meu entender, um dos conflitos centrais entre o Norte e o Sul resultará do confronto entre a democracia representativa e a democracia participativa. Esse confronto, que decorre do fato de a democracia representativa rejeitar a legitimidade da democracia participativa, só terá solução na medida em que essa recusa for substituída pelo delineamento de formas de complementaridade entre as duas formas de democracia que contribuam para o aprofundamento de ambas. Nesta complementaridade reside um dos cami-

\footnotetext{
${ }^{3}$ Neste sentido, vide a profusão de comentários contrários ao Decreto 8.243/14, que pretendia instituir a Política Nacional de Participação Social - PNPS, e foi rechaçado pela parcela política mais conservadora, que a caracterizou como "bolivariano".
}

nhos da reinvenção da emancipação social. (SANTOS, 2002, p.32)

O fato é que ambas as tipologias democráticas contêm pontos positivos e negativos, e apenas se beneficiariam de uma relação com maior reciprocidade. Aliás, mesmo a Democracia Direta, apesar de não constituir um sistema de governo próprio no Brasil, possui alguns instrumentos na política nacional, como plebiscitos e referendos, sem que a coexistência entre estes e os políticos deteriore a qualidade da Democracia Participativa. Muito pelo contrário, aliás.

Um dos referidos pontos positivos da Democracia Participativa é a possibilidade de segmentos organizados da Sociedade Civil qualificarem o processo democrático, justamente, pela participação. Contudo, não por uma participação qualquer, mas aquela caracterizada como social.

Segundo Carvalho (1995), três são os tipos de participação: a comunitária, a popular e a social. A participação comunitária completa o Estado, intervindo em suas relações com organizações e movimentos populares, ao fornecer aos sujeitos destas realidades espaços de debates, mas dotados apenas de funções opinativas e consultivas, não deliberativas. As mudanças propostas por este tipo de participação são pontuais, referentes a uma comunidade específica, tendo como exemplos as associações de bairro.

"É assim que se desenvolvem, ao lado é à sombra da proposta oficial da participação comunitária, experiências que, progressivamente, se radicalizam e terminam por assumir identidade própria, como propostas de participação popular" (CARVALHO, 1995, p.20). A tipologia popular de participação é, de fato, mais radical do que a anterior, por buscar o combate com o Estado. A questão da segmentação sócio-política é introduzida de forma mais contundente, com uma crítica aprofundada e práticas opostas ao sistema dominante. O Movimento dos Trabalhadores Sem-Terra - MST é um exemplo desta tipologia de participação, especialmente nos seus anos de formação, dotado de um caráter ainda pouco institucionalizado.

Por último, a participação social visa controlar o Estado, adotando um sentido de cidadania. Todos são reconhecidos, e interesses e projetos diversos são debatidos. Esta participação gera o modelo atual de democracia participativa, na 
qual a "dinâmica democrática estaria centrada na influência que os sujeitos coletivos pudessem exercer, em termos de demandas e controle, sobre o aparato estatal" (DURIGUETTO, 2011, p.293).

O conceito de participação social, portanto, tem seu cerne na concretização do controle social. Mas importa destacar que o termo "controle social" é definido de diversas formas, segundo a disciplina enfocada ${ }^{4}$. E mesmo partindo de concepções políticas, a expressão é ambígua, assumindo dupla significação, no que tange a relação entre Estado e Sociedade Civil.

A primeira é a que entende controle social como controle do Estado sobre a sociedade. Segundo essa concepção, o Estado controla a sociedade em favor dos interesses da classe dominante implementando políticas sociais para amenizar os conflitos de classe. Por trás dessa perspectiva está a concepção de 'Estado restrito', ou seja, a de Estado como administrador dos negócios da classe dominante. [...]

A segunda concepção entende o controle social como controle da sociedade (ou de setores organizados da sociedade) sobre as ações do Estado. Desse ponto de vista, a sociedade tem possibilidades de controlar as ações do Estado em favor de interesses das classes subalternas. Por trás dessa perspectiva está a concepção de "Estado ampliado', segundo a qual o Estado é visto como perpassado por interesses de classes, ou seja, como um espaço contraditório que, apesar de representar hegemonicamente os interesses da classe dominante, incorpora demandas das classes subalternas. (CORREIA, 2005, p.48-49).

Como há de ser analisado no tópico a seguir, as Conferências Municipais são instâncias que, formadas por segmentos da Sociedade Civil, permitem a inserção de pautas e debates por eles iniciados na agenda governamental. Deste

\footnotetext{
4 "Na sociologia, a expressão 'controle social' é utilizada para designar os mecanismos que estabelecem a ordem social disciplinando a sociedade, submetendo os indivíduos a determinados padrões sociais e princípios morais. [...] Na psicologia, a dimensão subjetiva do controle social é tratada por Freud, que concebe o superego como a absorção das normas sociais pela estrutura da personalidade, fazendo com que se introjete, assim, no indivíduo, o próprio conteúdo desse controle" (CORREIA, 2005, p.48). $\mathrm{E}$ há também as definições presentes na política e na economia, tratadas no texto
}

modo, é uma tentativa de se concretizar o segundo tipo de controle social, ou seja, aquele em que um Estado ampliado se faz necessário, de modo a abarcar demandas democráticas e sujeitos diversos.

Para tanto, os órgãos participativos, compostos por segmentos da Sociedade Civil organizada, atuam de modo a, em alguns casos, fiscalizar a atividade estatal e, noutros, direcioná-la. Como há de ser analisado a seguir, as Conferências Municipais de Saúde enfocam sua atuação no segundo caso, ou seja, no direcionamento - ou, ao menos, na tentativa - das políticas públicas de saúde mais progressistas e emancipatórias.

\section{As Conferências Municipais de Saúde}

Seguindo tais predisposições (fiscalizatória e diretiva), os Conselhos de Políticas Públicas e suas Conferências se complementam. O Conselho Municipal de Saúde de Ponta Grossa, por exemplo, tem "funções de assessoramento, fiscalizadoras, deliberativas e consultivas" (PONTA GROSSA, 1992), mas tem na fiscalização a principal atividade. As Conferências organizadas pelo Conselho, por outro lado, têm como principais obrigações "I. Avaliar a situação atual da saúde no município; II. Formular a Política Municipal de Saúde no âmbito do município de Ponta Grossa [...]" (PONTA GROSSA, 2011). Destarte, há uma inter-relação entre estes órgãos, já que "os Conselhos têm o papel formal de zelar e trabalhar para que as proposições das Conferências sejam implementadas." (KRÜGER et. al., 2012, p.121).

Visto que tanto os Conselhos quanto as Conferências de Saúde são constituídos, em sua maioria, por representantes da Sociedade Civil, estas instâncias participativas passam, em teoria, a realmente exercer um controle social sobre o aparato estatal. Não obstante, a execução da política de saúde - assim como de outras políticas sociais - continua a ser de competência estatal $^{5}$; mas é fato que a partir da implementação das ferramentas democrático-participativas em questão, esta política passa a ser planejada em

\footnotetext{
${ }^{5} \mathrm{~A}$ competência originária da execução da política de saúde é do Estado, mas a rede privada, autorizada pelo Estado, oferece um serviço indireto e complementar ao público.
} 
conjunto com os membros da Sociedade Civil; e, além disso, fiscalizada por estes.

É compreensível, portanto - ainda mais considerando a, até então, recente história de desenvolvimento da Democracia brasileira -, a contrapartida receosa da Sociedade Política, não facilitando a tomada de uma posição muito ativa nas relações de poder, pelos sujeitos provindos da Sociedade Civil organizada. Assim, forças opostas, mas convergentes no fim de se empoderar, constituem a política democrática brasileira. E a palavra "constituir" não é utilizada de gratuitamente, visto que tanto os Conselhos como as Conferências são integrantes do Sistema Único de Saúde - SUS e, portanto, da Administração Pública.

A contraposição entre os interesses políticos e os sociais é evidente nestes espaços, até porque os órgãos em questão foram gerados num período conturbado de redemocratização, característico de uma "distensão lenta, gradual e segura”, e por inúmeras reivindicações populares.

No setor da saúde, inclusive, tal caráter dúbio é comprovado pela existência de duas leis federais que regulamentam o SUS: a Lei 8.080, de 19 de setembro de 1990, cujos dispositivos sobre participação social foram vetados pelo então Presidente Fernando Collor de Mello. Mas, ainda em 1990, em 28 de dezembro, depois de muita pressão social e política, foi promulgada a Lei 8.142, que recuperava as normas vetadas, incorporando de vez o caráter participativo ao SUS, principalmente por meio dos Conselhos de Saúde e suas Conferências. E esta tensão entre interesses provindos do meio político e do meio social é ainda mais facilmente verificável a nível municipal, onde as diferenças e relações de poder são mais visíveis.

Ocorre que os Conselhos Municipais de Saúde, em geral, possuem uma natureza jurídica deliberativa, o que confere às suas resoluções uma obrigatoriedade, ou seja, devem ser acatadas - ou, no mínimo, analisadas - pela Administração Pública; mas às Conferências não é dada tal prerrogativa. Nas CMSPG, vale dizer, a situação não é diferente, pois enquanto - como já demonstrado no início desta seção - o Conselho possui natureza deliberativa, as Conferências são apenas consultivas, segundo lei municipal correspondente (PONTA GROSSA, 1992).
Desta feita, os relatórios finais das Conferências contêm inúmeras ações estratégicas, mas, por serem dotadas apenas de natureza consultiva, podem ou não ser incluídas nos planos de governo, servindo apenas de sugestões, e muitas vezes sequer sendo examinadas.

Se, de fato, as Conferências Municipais de Saúde enfrentam problemas externos em sua relação com a Administração Pública, vale apontar que também existem numerosos problemas internos. Os delegados das Conferências de Saúde Brasil afora, representando suas respectivas entidades, são divididos, segundo o princípio da paridade, da seguinte forma: "a) $50 \%$ de entidades de usuários; b) $25 \%$ de entidades dos trabalhadores de saúde; c) $25 \%$ de representação de governo, de prestadores de serviços privados conveniados, com ou sem fins lucrativos" (BRASIL, 2003).

Há, neste sentido, um estímulo para que seus segmentos sejam compostos por sujeitos e entidades representativos de diferentes setores, vivências e realidades, numa experiência de comunicação plural e participação democrática. Experiência esta, contudo, que depende da presença destes sujeitos, e não somente de tal fator, mas também de uma participação qualificada dos mesmos neste processo.

E é fato que o comparecimento dos delegados nas CMSPG de 2009 e 2011, constatado a partir das listas de presença, não condiz com o previsto pelo regulamento ${ }^{6}$. $\mathrm{Na} 8^{a} \mathrm{CMSPG}$, de um total de 200 delegados previstos, apenas 122 compareceram (61\%), e destes somente 27 eram usuários, enquanto 50 correspondiam a trabalhadores da saúde. Já na CMSPG posterior, o respectivo regulamento aumentou a previsão total de delegados para 304 , mas a presença foi ainda menor, apenas $82(27 \%)$, mas, ao menos, destes 37 eram usuários, numa proporção mais próxima à buscada pelo princípio da paridade.

$E$, infelizmente, tal situação não é exclusividade de Ponta Grossa, sendo observada também

\footnotetext{
${ }^{6}$ As listas de presença das referidas CMSPG, guardadas pelo Conselho Municipal de Saúde, foram consultadas somente depois de aceite o ofício enviado ao conselho - com requisição específica para tanto, assim como após aprovação do projeto de pesquisa submetido, em 12/03/2014, à Plataforma Brasil, cujo número CAAE é o seguinte: 28921714.0.0000.0105. Para maior informação sobre a presença dos delegados nas CMSPG, vide Miranda (2014).
} 
em outras Conferências, não apenas municipais ou de saúde, mas em espaços participativos no geral (DAGNINO, 2002; KRÜGER et al., 2012; LUIZ, I. C, 2011, dentre outros), o que denota uma cultura política brasileira de baixa participação, além da descrença generalizada nos processos políticos e instâncias sociais.

Outrossim, como afirmado, a baixa presença nas Conferências é evidenciada, paralelamente, à participação não qualificada nestes espaços. Em outras palavras, mesmo quando presentes os delegados, estes podem virem a ser espectadores, sem participarem ativamente dos debates e inserções de conteúdo.

Em face das (in)formações diversas, ocorre dos sujeitos que compõem as CMSPG possuírem graus desiguais de poder, de capacitação e de conhecimento sobre o que são as Conferências, o que fazem e quais seus objetivos.

Não advogamos, por certo, contra a heterogeneidade compositiva das Conferências, pois ela é vital para sua atuação democrática. "A pluralidade na composição, em vez de um obstáculo - como alguns estudos têm sugerido - é, ao contrário, o elemento que responde pela natureza pública e democrática desses novos arranjos [...]" (TATAGIBA, 2002, p.54).

Uma avaliação mais produtiva, inclusive do ponto de vista político, enquanto interessados no aprofundamento da democratização brasileira, deve partir do reconhecimento da complexidade desse processo e da diversidade dos contextos, envolvendo a multiplicidade de relações entre forças políticas onde ele se dá [...] (DAGNINO, 2002, p.297)

Porém, é inegável que a falta de capacitação de alguns membros das CMSPG pode levar a uma atuação fora dos padrões inicialmente desejados para estas instâncias. É óbvio que a situação destes sujeitos não pode lhes ser imputada segundo sua própria vontade. Os delegados, conselheiros e participantes em geral destes colegiados não possuem capacitação, informação e/ou conhecimento não porque assim o desejam, mas, em primeiro lugar, pela complexidade da sociedade na qual vivem.

[...] à medida que as sociedades passaram de uma economia familiar para uma economia de mercado, de uma economia de mercado para uma economia protegida, regulada e planifi- cada, aumentaram os problemas políticos que requerem competências técnicas. Os problemas técnicos exigem, por sua vez, expertos, especialistas... Tecnocracia e democracia são antitéticas: se o protagonista da sociedade industrial é o especialista, impossível que venha a ser o cidadão comum. (BOBBIO, 1986 apud SANTOS, 2002, p.47).

O que ocorre é que tal situação persiste pela partilha desigual do conhecimento, marcada por uma estratificação classista que concentra o saber em certos nichos, beneficiando-os pela desinformação alheia. Assim, esta incapacidade é tolerada pelos sujeitos dominantes e, até mesmo, incentivada. "Toda a prática profissional ou social que tenha a intenção de ser emancipatória, num contexto capitalista e neoliberal, vai se defrontar com um quadro estrutural que limita tal intenção" (LUIZ, 2011, p.239).

Como resultado desta situação desigual de conhecimento, o tecnicismo, ainda que por vezes necessário, torna-se um instrumento de segregação, como revela a análise de Wendhausen e Caponi (2002 apud PEREIRA NETO, 2012, p.35):

O que se constata aí é a velha prática de técnicos falando para leigos, ou o que poderia ser pior, o uso instrumental de um espaço que se pretendia "democrático", para legitimar ações governamentais e não para "controla-las" e avalia-las, como seria a proposta inicial para os Conselhos.

Por certo que este desnível entre os delegados acaba por desfavorecer aqueles com menos conhecimento, informação ou mesmo capacidade deliberativa, o que tende a ocorrer com mais frequência, segundo os estudos nesta temática, entre os representantes dos usuários. Inclusive por esta razão, a concretização do princípio da paridade faz-se importante, fator que, infelizmente, como já visto, não é sempre uma realidade.

Em face destas determinantes - negligência do Poder Público para com as instâncias participativas; cultura política de baixa participação; falta de conhecimento e informação dos membros que constituem estas ferramentas democráticas; e relações de poder desiguais entre os segmentos -, dentre muitas outras aqui não abordadas, as CMSPG acabam por não ter uma atuação satisfatória. 
Um dos sintomas desta situação não ideal é que o documento derradeiro das CMSPG - o Relatório Final - acaba por agregar ações estratégicas que, examinadas de forma mais minuciosa, se revelam desconexas daquela realidade, simplesmente por não se conectarem à política de saúde. É, portanto, ao exame de tais ações, em especial nos relatórios das CMSPG de 2009 e 2011 que passaremos neste momento.

\section{OS RELATÓRIOS FINAIS DAS $8^{\mathrm{a}}$ E $9^{\mathrm{a}}$ CONFERÊNCIAS MUNICIPAIS DE SAÚDE DE PONTA GROSSA E AS AÇÕES ESTRATÉGICAS DESCONECTADAS}

O processo realizado pelas CMSPG pode ser considerado trifásico. Num primeiro momento, os delegados eleitos - sujeitos representantes de entidades, provindas da sociedade civil - que as compõem vocalizam seus interesses sobre a política municipal de saúde. Posteriormente, estes interesses são coletivamente considerados ou descartados, em plenária, como ações estratégicas na redação do Relatório Final de tal instância. Quando findo, este documento, por sua vez, é enviado para a Administração Pública, que o analisa, podendo materializar ou não as ações estratégicas dos Relatórios em seus planos de governo.

Em nossa pesquisa, colhemos dados quantitativos sobre o segundo e o terceiro momentos das $8^{\text {a }}$ (2009) e $9^{\text {a }}$ CMSPG $(2011)^{7}$, ou seja, sobre a composição de seus Relatórios Finais, bem como sobre a recepção de suas ações estratégicas pelo Poder Público em seu plano plurianual (2010-2013) e anual de saúde (2012).

Antes de apresentarmos tais dados, porém, é necessário compreender que Ponta Grossa é um município com um histórico conservador, desenvolvido a partir de latifúndios.

Entre o final do século XIX e o início do século $X X$, a cidade passou por inúmeras transformações de ordem socioeconômica: advento das ferrovias, urbanização, crescimento do comércio e da indústria; novos atores so-

\footnotetext{
${ }^{7}$ Do ano de 1995 a 2011, as CMSPG foram realizadas sempre no intervalo de 2 anos, seguindo o calendário estadual das Conferências de Saúde paranaenses. Apenas em 2011, decidiu-se que seriam realizadas a cada 4 anos, coadunando-se ao novo calendário estadual e o já assim preconizado nacional.
}

ciais que passaram a compor o cenário pontagrossense com a chegada dos imigrantes europeus. No entanto, no que se refere às estruturas de poder, estas permaneceram inalteradas ao longo do século XX. O poder local tem estado, historicamente, irremediavelmente ligado a interesses de grupos políticos, os quais irão conduzir o processo de modernização da cidade a partir de sua lógica conservadora. (SCHIMANSKI, 2007, p.89-90)

Neste processo, o conservadorismo é concretizado pelo apoio ao Estado Novo e mesmo ao Regime Militar, ideologia proferida pela perene classe dominante, a qual sentia-se no direito de concentrar o poder, "já que conduzira todo processo de emancipação política da cidade. A 'dívida' com o patronato local limita e cerceia o desenvolvimento econômico e social da sociedade pontagrossense ainda hoje." (SCHIMANSKI, 2007, p.96). E tal débito não é esquecido, pois os nomes e sobrenomes destes cidadãos estão eternizados em ruas, avenidas, praças e nomes de edifícios.

Os princípios econômicos liberais continuaram vigorando no cenário local e, assim, boa parte dos políticos eleitos no município representava uma agenda mais conservadora. A própria eleição de Pedro Wosgrau Filho, em 2008, comprova a relação "satisfatória entre, por um lado, a noção ideológica de conservadorismo e patrimonialismo (que incluem ricos e também pobres) e, por outro, a manutenção de pelo menos 12 anos de poder político. " (GOIRIS, 2013, p.247).

A gestão 2009-2012 de Wosgrau (PSDB) seguiu os rumos das gestões anteriores, sendo sua terceira à frente do executivo pontagrossense. E é sobre esta gestão que o recorte de pesquisa foi realizado. Inclusive, sendo a política municipal de saúde o enfoque do presente trabalho, vale apontar a situação da mesma na referida gestão:

Um dos grandes questionamentos do governo Wosgrau Filho refere-se à questão da saúde, que de promessa de campanha se transformou em verdadeiro pesadelo para as pessoas que procuravam os serviços públicos de saúde do município. Falta de atendimento médi$\mathrm{co}$, leitos - especialmente de UTI - em completa defasagem com os usuários, número de profissionais exíguo, falta de medicamentos básicos, etc., foram o calidoscópio que du- 
rante todo o seu governo ocuparam inclusive as páginas dos jornais locais. (GOIRIS, 2013, p.250)

Neste período, em relação à participação social na política de saúde, como já afirmado, ocorreram duas CMSPG, a $8^{\mathrm{a}}$ e a $9^{\mathrm{a}}$, as quais produziram, cada qual, seus Relatórios Finais, com as seguintes configurações quantitativas de ações estratégicas, divididas didaticamente para esta pesquisa em eixos operacionais.

TABELA 1 - Número de ações estratégicas de cada eixo operacional, e sua significância sobre o total de ações propostas nas $8^{a}$ (2009) e $9^{a}$ (2011) CMSPG

\begin{tabular}{l|l|l}
\hline \multirow{2}{*}{ Eixos operacionais } & \multicolumn{2}{c}{ No de ações estratégicas dos Relatórios Finais $^{*}$} \\
\cline { 2 - 3 } & $\begin{array}{l}\text { Ações do Relatório Final da 8 } \\
\text { CMSPG }-2009 \text { (significância) }\end{array}$ & $\begin{array}{l}\text { Ações do Relatório Final da 9a } \\
\text { CMSPG - 2011 (significância) }\end{array}$ \\
\hline Atenção à Saúde & $52(33,5 \%)$ & $73(34 \%)$ \\
\hline Gestão do SUS & $38(24,5 \%)$ & $52(24,2 \%)$ \\
\hline Política de saúde & $23(14,8 \%)$ & $25(11,6 \%)$ \\
\hline Participação da comunidade & $5(3,2 \%)$ & $12(5,6 \%)$ \\
\hline Educação e informação em saúde & $8(5,2 \%)$ & $22(10,2 \%)$ \\
\hline Ciência e tecnologia em saúde & $0(0 \%)$ & $3(1,4 \%)$ \\
\hline OUTRAS & $28(18 \%)$ & $27(12,5 \%)$ \\
\hline Total & $155(100 \%)$ & $215(100 \%)$ \\
\hline
\end{tabular}

Fonte: organizada pelos autores, a partir dos dados coletados nos relatórios finais das $8^{\text {a }}$ e $9^{a}$ Conferências Municipais de Saúde de Ponta Grossa (PONTA GROSSA, 2009 e 2011).

Ainda que cada eixo operacional tenha sua importância para o Relatório Final das CMSPG, focaremos nossas percepções sobre apenas um eixo, o denominado "Outras". Todos os demais eixos têm uma relação direta com a política municipal de saúde, mesmo o intitulado "Participação da comunidade", já que se refere à presença, direta ou indireta, de cidadãos nas decisões desta política. O eixo "Outras", porém, tem caráter residual, pois compreende ações não relativas aos eixos anteriores, não conectadas diretamente ao SUS e/ou à política de saúde propriamente dita. Vejamos que os relatórios finais das $8^{\mathrm{a}}$ e $9^{\mathrm{a}} \mathrm{CMSPG}$ se assemelham neste setor, apresentando 28 (vinte e oito) e 27 (vinte e sete) ações estratégicas, que representam 18\% e $12,5 \%$ destas ações nos respectivos relatórios.

Em ambos os relatórios, tais porcentagens colocam este eixo em terceiro lugar de significância. $E$ isto é preocupante, pois, em sua grande maioria, tais ações versam sobre temas relativos a planejamento urbano, agricultura familiar, reforma agrária, educação no trânsito, dentre outras ações que não deveriam, em tese, ser propostas pelas CMSPG. Uma pergunta direta e, supostamente, simples - "Que ações interessam a uma conferência municipal de saúde?” - sequer encontra uma resposta, a partir da análise dos Relatórios Finais em questão.

A grande presença destas ações estratégicas desconectadas, em ambos os documentos analisados, indica uma falha na percepção de qual o objetivo na proposição de tais ações, que é, afinal, formular a política de saúde. Tais ações estratégicas, desconectadas da política municipal de saúde, acabam por impedir uma redação coesa do relatório final das CMSPG.

Uma vez que parte dos relatórios finais das CMSPG propõe assuntos não diretamente correlatos à política municipal de saúde, a Administração Pública, via Secretaria Municipal de Saúde, tem mais razões para desconsiderar estas ações estratégicas (além daquelas movidas por interesses políticos e, até mesmo, falta de orçamento, dentre outras). No montante destas "outras" ações desconsideradas, aquelas mais importantes também entram neste bojo, somando-se num total, como há de se ver, alarmante. Afinal, num universo de 155 (em 2009), ou 215 ações (em 2011), mais uma ou outra a ser desconsiderada não fará grande diferença.

Todavia, há de se registrar que esta pluralização de demandas, no âmbito da participação municipal, reflete uma realidade também 
observada nas Conferências Nacionais de Saúde. A primeira delas, realizada em 1986 e que estruturou as bases do SUS, contava com apenas 49 proposições em seus 3 eixos (saúde como direito; reformulação do sistema nacional de saúde; e financiamento do setor), totalmente conexos à política de saúde pretendida à época (BRASIL, 2016). E ainda que também contivesse vários subitens dentro de algumas destas propostas, a pluralização de demandas com o passar dos anos fica evidente, ao se comparar o relatório de 1986 com o da $14^{\text {a }}$ Conferência Nacional, de 2011 (BRASIL, 2012). Este documento continha um total de 343 premissas, divididas em 15 eixos temáticos, demonstrando, de modo inegável, a complexidade da política de saúde brasileira.

O fato é que - seja por falta de capacitação, por desconhecimento, pela ausência de outros espaços que tenham por finalidade direta cuidar destas ações estratégicas, quando muito apenas indiretamente ligadas à política de saúde - um número considerável de "ações estratégicas desconectadas" é aprovado nos Relatórios Finais das CMSPG. E assim, se as CMSPG começam por auxiliar a "Formular a Política Municipal de Saúde no âmbito do município de Ponta Grossa [...]" (PONTA GROSSA, 2011), terminam por também propor ações que, em teoria, não seriam de sua alçada.

E se o aspecto quantitativo do eixo "Outras" evidencia certa confusão quanto às ações estratégicas das CMSPG, a própria redação destas é outro indicativo da situação. Ambos os relatórios finais examinados apresentam ações repetidas e, além disso, uma considerável porção de suas ações não possuem metas a serem cumpridas, prazos estabelecidos ou mesmo objetivos claros.

Vejamos abaixo, respectivamente, o texto de apenas algumas ações estratégicas presentes nos Relatórios Finais das $8^{\mathrm{a}}$ e $9^{\mathrm{a}} \mathrm{CMSPG}$ :

- Criar parques (áreas verdes) e áreas de lazer para visitação e atividades físicas no município; - Criar ciclovias conectando os bairros ao centro da cidade; - Definir um programa de merenda escolar oriunda de produtos agroecológicos; - Implementar a reforma agrária no Brasil com condições de fixação das famílias no campo e incentivos à produção ética e sustentável; - Promover e fomentar a economia solidária na agricultura familiar, a reforma agrária, para que haja mudança nos mo- dos de produção e consumo; - Implementar a lei que obriga a cada escola municipal ter um professor de educação física orientando e ensinando as crianças a prática correta de atividades físicas; - Garantir o registro geral animal (RGA): microchip (transponde subcutâneo) com numeração relacionada aos dados do responsável pelo animal, em todo o município; - Realizar um programa efetivo de transferência de famílias das áreas de risco (em torno dos arroios e outros) para locais com estrutura necessária, garantindo a meIhoria da qualidade de vida das famílias e a proteção ambiental. (PONTA GROSSA, 2009)

- Garantir acessibilidade nas vias públicas do município; - Construção e/ou remodelação das calcadas e passeios próximo das escolas e vias públicas e postos de Saúde, com pavimentação antiderrapante; - Campanha para educação no transito, e mais radares na cidade; - Sugerir nas áreas rurais o policiamento tanto da guarda municipal como da Polícia Militar; - Melhorar o controle dos gazes [sic] poluentes em todo o município; - Que aja [sic] mais rigor na fiscalização dos veículos motores dentro do município contra poluentes; Quadra poliesportiva cobertas; - Construção de ciclovias; - Mais patrulhamento e segurança em todas escolas; - Pavimentação nas ruas de ônibus; - Sugerir maior segurança nos bairros com visitas mais periódicas da corporação de segurança do Estado (posto policial). (PONTA GROSSA, 2011)

Reconhecemos que a saúde pública é composta por variáveis não ligadas diretamente à política de saúde em si, como alimentação, controle de animais e cuidado com o meio-ambiente. Todavia, por analogia, a educação também depende de ruas pavimentadas para que o aluno chegue à escola, mas não é a Conferência Municipal de Educação a instância que deveria se preocupar com tal situação. Por certo que não pretendemos afirmar que a pavimentação de ruas, o controle de animais ou o cuidado com o meio-ambiente não constituem demandas importantes - ou mesmo, fundamentais -, mas apenas indicar sua oblíqua ligação com a finalidade primeira do foro participativo aqui analisado, as CMSPG.

Moroni aponta a necessidade de uma melhor articulação destes foros participativos, os quais possuem objetivos diferenciados, mas todos voltados para a consecução das políticas públicas. Segundo o autor, é preciso 
Estabelecer comunicação e relação política entre os diferentes espaços - conselhos e conferências -, que até agora têm permanecido estanques, verticais, fragmentados e sem ligação. Como a Conferência das Cidades, por exemplo, comunica-se com a questão da criança, com a questão da segurança, com a questão do meio ambiente? (MORONI, 2009, p.139)

Sem uma articulação entre os espaços que debatem as diferentes políticas públicas municipais, as proposições provindas destas instâncias podem encontrar, dentre outros desfechos, dois bastante prováveis: conflitos com outras ações e/ou carência de confiança. Expliquemos.

É possível que duas ações versando sobre o mesmo tema (asfaltamento, por exemplo) sejam propostas por diferentes instâncias colegiadas, digamos a Conferência Municipal de Saúde e o Conselho Municipal de Transporte. Havendo falta de comunicação entre estes espaços, nos parece que a probabilidade destas ações se conflitarem é grande. E, chegando à Administração Pública, no mínimo uma delas será descartada, quando não ambas.

Diante de tal situação, é de se imaginar que a demanda provinda do Conselho de Transporte será considerada mais legítima, por se tratar de uma ação relativa à asfaltamento. Destarte, a ação proposta pelo CMSPG, mas desconectada da política de saúde, acaba por não conter grande respaldo para se materializar no respectivo plano de governo.

Ocorre também que as propostas resultantes do plenário, durante o processo de debate, de relatoria e de aprovação perdem um pouco de seu sentido original. É um processo saturado por contradições, uma vez que muitas reivindicações estão aquém dos princípios constitucionais em relação aos direitos sociais e aos de saúde, outras são contraditórias em relação aos princípios de universalidade e integralidade por priorizarem necessidades de determinados grupos sociais ou interesses corporativos (KRÜGER, 2005 apud KRÜGER, 2009)

Neste sentido, as ações estratégicas caracterizadas, por nossa pesquisa, como do eixo operacional "Outras" obtiveram baixa materialização nos planos governamentais. No plano plurianual de 2010-2013, apenas 5 (cinco) das
28 (vinte e oito) "outras" ações foram incluídas em tal plano de governo, o que corresponde a apenas $17,8 \%$ deste total. Já no plano seguinte, o anual de 2012, nenhuma das 27 (vinte e sete) "outras" ações foi incluída.

É verdade, porém, que o percentual dos demais eixos operacionais (Atenção à Saúde; Gestão do SUS; Política de saúde; Participação da comunidade; Educação e informação em saúde; Ciência e tecnologia em saúde, todos eles analisados na dissertação de mestrado que deu origem a este artigo) também não atingiu patamares elevados, mas o fato é que no plano plurianual, o eixo "Outras" obteve a quarta posição de materialização. E no plano seguinte ficou em último lugar.

Uma vez entregues os Relatórios Finais das CMSPG ao Poder Público, este percebe que há ações estratégicas que são, de fato, da alçada desta instância, o que o obriga a considerá-las e, em alguns casos, incluí-las nos planos de governo. Contudo, as ações desconectadas da função primária deste colegiado constituem um verdadeiro problema, pois são, segundo os números coletados, excluídas dos futuros planos de governo.

Em resumo, as CMSPG terminam por se preocupar com assuntos e temas que não especificamente seus. O enfoque da CMSPG é prejudicado, em vista da preocupação plural seja ela fruto de bons ou maus pretextos - desta instância, percebida pela Administração, que não materializa em seus planos de governo estas ações desconectadas da política de saúde. E, inclusive, a Administração Municipal se beneficia desta situação, pois, diante destas "outras" ações, há maior respaldo para desconsiderá-las, obtendo espaço para concretizar seus próprios interesses políticos.

Deste modo, ficam evidentes alguns dos percalços pelos quais os órgãos participativos têm de passar, sejam eles ocasionados por fatores endógenos (surgidos dentro das CMSPG) ou exógenos (do Poder Público para com as CMSPG), além dos resultados não satisfatórios provindos destes.

Por outro lado, os contratempos sofridos pela Democracia Participativa não são o suficiente para desconsiderar o potencial de seus instrumentos, órgãos e ferramentas, tais como as Conferências Municipais de Saúde. 
A gestão participativa não é uma operação isenta de obstáculos, dificuldades e problemas. Como todo processo de intensificação democrática, no qual veem à tona participantes até então excluídos do processo decisório e da vida pública, a gestão participativa é alvo de disputas, sofre ataques sistemáticos, torna-se objeto de cobiça ou pode ser afetada por manobras diversionistas dos que se sentem particularmente ameaçados ou incomodados. (NOGUEIRA, 2011, p.158)

O Brasil, enfim, se caracteriza por esta realidade multifacetada. Possui uma política representativa com instrumentos de democracia direta e participativa; seus cidadãos são titulares de direitos fundamentais e também beneficiados por ações afirmativas; é dotado de políticas redistributivas, mas suas desigualdades sociais e econômicas continuam imensas.

Os espaços das Conferências e Conselhos, mesmo que formalmente delimitados [...], estão possibilitando que muitos representantes da sociedade, grupos sociais historicamente excluídos (usuários/trabalhadores) e muitos servidores públicos adentrem as autoritárias fronteiras que marcam a história da administração pública brasileira e façam proposições sobre as políticas públicas. Ainda, se constituem como oportunidade de socialização da política e de construção de uma outra hegemonia articulada pelos princípios da democracia. (KRÜGER, et al., 2011, p.509)

O Brasil é, enfim, um Estado com várias contradições, mas, em suma, com uma Democracia em desenvolvimento. E, portanto, a proposição pelas CMSPG de ações estratégicas desconectadas de sua finalidade é um indicativo desta situação, que ainda ter por onde se desenvolver. Para que uma Democracia efetivamente participativa possa erigir - não contra a Democracia Representativa e a Administração Pública -, mas num caminho conjunto, rumo a um controle social de fato.

\section{Considerações finais}

A existência dos instrumentos de Democracia Participativa na política nacional é uma realidade há muito presente, ainda que desconhecida de parte da população brasileira. Dentre estes instrumentos, há as Conferências
Municipais de Saúde que, conjuntamente aos Conselhos que as organizam, possibilitam a vocalização de interesses de segmentos da Sociedade Civil acerca da política municipal de saúde.

Desde 1995, as Conferências Municipais de Saúde de Ponta Grossa constituem um espaço de debate, proposição de ideias e interesses, de uma forma paralela e complementar à Democracia Representativa, de modo que esta avalie o Relatório Final daqueles colegiados, incluindo ou não suas ações estratégicas em seus planos de governo.

Ocorre que, por diversos fatores, demonstramos que a proposição de ações estratégicas pelas CMSPG não é realizada a contento, pois grande parte destas é desconectada da finalidade de "formular a política de saúde municipal" (PONTA GROSSA, 2011). Esta inegável pulverização dos debates na política de saúde pode trazer riscos para a sistematização da assistência de saúde, pecando pela falta de objetivação das demandas propostas. Analisando a $8^{\mathrm{a}}$ e a $9^{\mathrm{a}}$ CMSPG, demonstrou-se que $18 \%$ e $12,5 \%$ foram os percentuais correspondentes a estas ações desconexas nos respectivos Relatórios Finais.

Tais percentuais não podem ser desconsiderados, pois as CMSPG, assim como as demais Conferências de Saúde são colegiados integrantes do SUS, que devem agir com o máximo de eficiência, com enfoque bem delimitado de suas funções. Se assim realizado, a política de saúde será melhor prestada ao indivíduo que dela necessita. Por outro lado, se focadas em problemas que não são de sua alçada - e, portanto, não há um conhecimento aprofundado destes por tais instâncias -, ocorrerá um desgaste de energia e mesmo uma desesperança que pode atingir os envolvidos neste processo. "Se os atores sociais mobilizam-se, mas as coisas não saem do lugar, eles retrocedem e deixam de participar." (NOGUEIRA, 2011, p.153).

Pode ocorrer, inclusive, de o Poder Público se beneficiar da situação, não considerando as ações desconexas. Como demonstrado pelos dados expostos, a Administração Pública pontagrossense, na terceira gestão do prefeito Wosgrau, incluiu poucas ações estratégicas do eixo "Outras" em seus planos de governo.

Portanto, a própria participação social é obstada de se inserir na Administração Pública, apesar de encontrar-se constitucionalmente 
garantida. Entendemos que as vertentes participativa e representativa da Democracia brasileira continuam a desenvolver-se paralelamente, quando, na realidade, deveriam comunicar-se transversalmente, de modo a suprirem simultaneamente suas falhas.

Neste sentido, se este ideal de comunicação entre representação e participação não ocorrer, esperamos, ao menos, que os vários órgãos, colegiados e instâncias participativas comuniquem-se entre si. As CMSPG, por exemplo, não precisariam constar em seus Relatórios Finais ações estratégicas sobre ciclovias ou merendas sustentáveis, mas, respectivamente, comunicar o Conselho de Trânsito e o de Educação. "O desafio é como o reconhecimento da riqueza da multiplicidade dos sujeitos políticos e de suas 'causas' não levem à fragmentação total da luta política." (MORONI, 2009, p.139).

Há de se pensar, portanto, como a inclusão destes sujeitos participativos pode desenvolver a Democracia brasileira como um todo, de modo a promover uma comunicação permanente e frutífera entre os novos espaços, e destes com os tradicionais.

\section{Referências}

BRASIL. Constituição da República Federativa do Brasil. Brasília, 5 de outubro de 1988.

BRASIL. Ministério da Saúde. Conselho Nacional de Saúde. Relatório final da $\mathbf{8}^{\mathrm{a}}$ Conferência Nacional de Saúde. Brasília: Ministério da Saúde, 1986. Disponível em: <http://conselho.saude.gov.br/ biblioteca/Relatorios/relatorio_8.pdf>. Acesso em 15 de março de 2016.

BRASIL. Ministério da Saúde. Conselho Nacional de Saúde. Relatório final da $14^{\text {a }}$ Conferência Nacional de Saúde: todos usam o SUS: SUS na seguridade social: Política pública, patrimônio do povo brasileiro. Brasília: Ministério da Saúde, 2012. Disponível em: <http://conselho.saude.gov.br/14cns/docs/Relatorio_ final.pdf>. Acesso em 03 de janeiro de 2016.

BRASIL. Ministério da Saúde. Conselho Nacional de Saúde. Resolução n. ${ }^{\circ}$ 333, de 4 de novembro de 2003. Aprova as diretrizes para criação, reformulação, estruturação e funcionamento dos Conselhos de Saúde. Brasília, 4 de dezembro de 2003. Disponível em: <http://conselho.saude.gov.br/biblioteca/livros/ resolucao_333.pdf>. Acesso em 03 jul. 2014.
CARVALHO, A. I. de. Conselhos de saúde no Brasil: participação cidadã e controle social. Rio de Janeiro: FASE/IBAM, 1995.

CORREIA, M. V. C. Desafios para o controle social: subsídios para capacitação de conselheiros de saúde. Rio de Janeiro: editora Fiocruz, 2005.

DAGNINO, E. Sociedade civil, espaços públicos e a construção democrática do Brasil: limites e possibilidades. In: Sociedade civil e espaços públicos no Brasil. Rio de Janeiro: Paz e Terra, 2002. p.279-303.

DURIGUETTO, M. L. Democracia: apontamentos do debate liberal e marxista. Revista Emancipação. Ponta Grossa: Editora UEPG, v.11, n.2, jul./dez., 2011.

GOIRIS, F. A. J. Estado e política: a história de Ponta Grossa. Ponta Grossa, Gráfica Planeta, 2013.

KRÜGER, T. R. As decisões sobre as políticas sociais: qual a influência da participação da sociedade? In: XIX Seminario Latinoamericano de Escuelas de Trabajo Social, 4 a 8 de outubro de 2009, Guayaquil, Equador. EI Trabajo Social en la conyuntura latinoamericana: desafios para su formación articulación y acción profesional. Guayaquil: ALAEITS, 2009. Disponível em: <www.ts.ucr.ac.cr/binarios/congresos/reg/slets/ slets-019-142.pdf> Acesso em 26 de novembro de 2012.

et al. As proposições das Conferências de Saúde e os Planos Municipais de Saúde: um estudo em municípios de Santa Catarina. Saúde em Debate. Rio de Janeiro, v. 35, n. 91, p. 508-521, out./dez. 2011.

et al. A organização e a dinâmica participativa dos segmentos sociais nas conferências municipais de saúde. Revista Emancipação. Ponta Grossa, v. 12, n. 1, p.119-130, jan./jun. 2012.

LUIZ, D. E. C. Emancipação e serviço social: a potencialidade da prática profissional. Ponta Grossa: Editora UEPG, 2011.

MIRANDA, P. F. M. Expressões Do Poder Local Na Materialização Das Conferências Municipais De Saúde De Ponta Grossa - 2009 E 2011. 2014. 256p. Dissertação (mestrado). Curso de Ciência Sociais Aplicadas - Universidade Estadual de Ponta Grossa, Ponta Grossa, 2014.

MORONI, J. A. O direito à participação no governo Lula. In: AVRITZER, L. (org.) Experiências nacionais de participação social. São Paulo: Cortez, 2009. p.107-141. 
NOGUEIRA, M. A. Um Estado para a Sociedade

Civil: temas éticos e políticos da gestão democrática. 3.ed. São Paulo: Editora Cortez, 2011.

PONTA GROSSA. Lei Municipal 4.728, de 07 de maio de 1992. Altera a redação do art. $2^{\circ}$ da Lei no 4658. Câmara municipal de Ponta Grossa, 1992. Disponível em: <http://www.jusbrasil.com.br/legislacao/419636/ lei-4728-92-ponta-grossa-pr>. Acesso em: 02 fev. 2014.

Relatório final da $8^{\mathrm{a}}$ conferência municipal de saúde de Ponta Grossa - 31/10/2009. Conselho Municipal de Saúde, 2009.

Plano municipal de saúde 20102013. Secretaria Municipal de Saúde, 2010.

Relatório final da $9^{a}$ conferência municipal de saúde de Ponta Grossa - 22 e 23 de julho de 2011. Conselho Municipal de Saúde, 2011.

Plano municipal de saúde 2012. Secretaria Municipal de Saúde, 2012.

ROUSSEAU, J.J. Do contrato social. 5. ed. São Paulo: Nova Cultural, 1991.

SANTOS, B. de S. Democratizar a democracia: os caminhos da democracia participativa. Rio de Janeiro: Civilização Brasileira, 2002.

SCHIMANSKI, E. Conservadorismo e tradição em Ponta Grossa: representação social, mito ou realidade na política local? 165 f. Dissertação (Mestrado em Ciências Sociais Aplicadas) - Universidade Estadual de Ponta Grossa, Ponta Grossa, 2007.

TATAGIBA, L. Os conselhos gestores e a democratização das políticas públicas no Brasil. In: DAGNINO, E. (org.). Sociedade civil e espaços públicos no Brasil. São Paulo: Paz e Terra, 2002. p.47-104.

TAVARES, A. R. Curso de direito constitucional. 6.ed. São Paulo: Saraiva, 2008.

WOLKMER, A. C. Ideologia, estado e direito. São Paulo: Revista dos Tribunais, 1995. 